\title{
VARIAÇÃO DOS SEDIMENTOS DE FUNDO E EVOLUÇÃO MORFOLÓGICA NO CORREDOR FLUVIAL DO RIO PARAGUAI, CÁCERES - MATO GROSSO
}

\author{
Gustavo Roberto dos Santos Leandro \\ Universidade Estadual Paulista "Júlio de Mesquita Filho" - UNESP, Faculdade de Ciências e Tecnologia - FCT, \\ Campus de Presidente Prudente, SP, Brasil \\ gustavogeociencias@hotmail.com \\ Célia Alves de Souza \\ Universidade do Estado de Mato Grosso - UNEMAT, Faculdade de Ciências Humanas - FCH, Pós-Graduação \\ em Geografia, Cáceres, MT, Brasil \\ celiaalvesgeo@globo.com
}

Flávio Rodrigues do Nascimento Universidade Federal do Ceará - UFC, Pós-Graduação em Geografia, Fortaleza, CE, Brasil flaviogeo@bol.com.br

\begin{abstract}
RESUMO
Os processos fluviais de erosão e deposição aferem o dinamismo do rio Paraguai com destaque para a progressiva evolução registrada nos ambientes de confluência com os rios Sepotuba e Cabaçal, bem como o complexo de baías e ilhas fluviais. Em trabalho de campo, foram identificadas agradação vertical e horizontal com a sucessão de vegetação pioneira. E, ainda, incorporação de depósitos arenosos a planícies, barras laterais e antigas ilhas fluviais a partir de análise visual de imagens - escala temporal. Portanto, os sedimentos de fundo apresentam importante papel na dinâmica desse sistema, principalmente por sua variação granulométrica. No período de cheia, apresentou maior heterogeneidade, diferente do registrado no período de vazante (material arenoso de textura fina). Nesse caso, há maior mobilidade de sedimentos no período chuvoso (entrada de água e sedimentos no sistema), enquanto no período de vazante ocorre a consolidação dos depósitos de canal. O monitoramento espaço-temporal de sua evolução, a partir de técnicas de campo, gabinete e laboratório, foi essencial, sobretudo pela importância da morfodinâmica de seus rios e pelos reflexos de sua evolução nos aspectos ambientais. Também, pelo uso e ocupação regionais com a navegabilidade no canal, e atividades associadas (pesca de subsistência e esportiva, lazer com balnealidade entre outras).
\end{abstract}

Palavras-chave: Sedimentos de fundo. Sistema fluvial. Rio Paraguai. Interações morfodinâmicas.

\section{VARIATION OF BOTTOM SEDIMENTS AND MORPHOLOGICAL EVOLUTION ALONG THE PARAGUAY RIVER'S CORRIDOR, CÁCERES - MATO GROSSO}

\begin{abstract}
The fluvial processes of erosion and deposition confirm the dynamism of the Paraguay River, highlighting the progressive evolution in the confluence environments with Sepotuba and Cabaçal Rivers, and complexes of bays and fluvial islands. On the fieldwork, vertical and horizontal gratifications were identified with the succession of pioneer vegetation. As well as, the incorporation of sandy deposits to the plain, lateral bars and old fluvial islands from visual analysis of images - temporal scale. Therefore, the bottom sediments play an important role in the dynamics of this system, mainly due to its granulometric variation. In the flooding period, it presented greater heterogeneity, different from that recorded in the ebbing period (sandy material of fine texture). In this case, there is greater sediment mobility in the rainy season (water and sediment entry into the system), while in the drought period, consolidation of the channel deposits. Therefore, the spatial-temporal monitoring of its evolution, from field, cabinet and laboratory techniques, becomes essential, mainly, due to the importance of the morphodynamics of its rivers and the repercussions of its evolution on regional environmental and socioeconomic aspects, such as navigability in the channel and associated activities.
\end{abstract}

Keywords: Bottom sediments. River system. Paraguay River. Morphodynamic interactions.

\begin{tabular}{|c|c|}
\hline & Uberlândia \\
\hline
\end{tabular}




\section{INTRODUÇÃO}

Os rios em seus segmentos aluviais são caracterizados pela dinâmica deposicional, ou seja, desenvolvem-se sobre seus próprios depósitos e, por isso, configuram ambientes frágeis às mudanças e/ou variações hidrológicas no sistema, igualmente, as atividades socioeconômicas que reordenam o uso/cobertura da terra. Como consequência, a combinação dos fatores mencionados fornece maior ou menor quantidade de sedimentos ao sistema fluvial. Nesse contexto, Bayer e Zancopé (2014) concluíram que os ambientes deposicionais/sedimentares associados ao canal principal mostram uma rápida evolução com elevadas taxas de migração, a exemplo do rio Araguaia. Nesse contexto, a preservação das geoformas deste subambiente está fortemente ligada ao regime hidrológico anual e às características da carga transportada, particularmente à grande disponibilidade de materiais arenosos no sistema.

Estudos em importantes sistemas fluviais têm sido desenvolvidos em várias partes do mundo. Ainda no século passado, Milliman et al. (1987) consideraram as influências das atividades humanas nos processos de erosão e transporte de sedimentos no rio Amarelo em uma perspectiva dos impactos em rios asiáticos. Nittrouer et al. (2008), já no século XXI, avaliaram o transporte de sedimentos no rio Mississipi por meio de novos métodos. Os autores monitoraram a migração das formas de leito quantificando o volume de material transportado. Ao considerar a dinâmica espaço-temporal, Nittrouer et al. (2012) também analisaram o comportamento da velocidade e a dinâmica de transporte de sedimentos no sistema fluvial do rio Mississipi. Nesse contexto, a distribuição da velocidade da água em um rio, é fortemente tridimensional, varia em cada lugar, seja no sentido vertical, transversal ou longitudinal, por isso, também é uma importante variável para a ocorrência dos processos fluviais (KUERTEN et al., 2009).

No Brasil, sistemas fluviais em seus trechos aluviais têm sido monitorados, principalmente a partir da segunda metade do século XX. Em estudo realizado no rio Ivaí Kuerten et al. (2009) destacaram que, em reflexo às constantes mudanças do fluxo, vazão e nível da água, os sedimentos contidos na corrente fluvial migram transversal e longitudinalmente ao longo das seções estudadas. Essa relação foi observada a partir das classes de sedimentos encontradas nos períodos de cheia e vazante, evidenciando um trabalho de seleção natural dos sedimentos hidrotransportados.

No rio Paraguai, a composição arenosa dos sedimentos de fundo, associada aos elementos biofísicos, contribui para alterações morfológicas. O canal principal e os ambientes fluviais proximais, tais como as baías, feições morfológicas ligadas ao canal principal, aferem a evolução atual do sistema em resposta ao constante trabalho hidrossedimentológico (SILVA et al., 2012; SOUZA et al., 2012; SOUZA et al., 2014).

Souza et al. (2012) destacaram ainda que o estágio evolutivo do corredor fluvial (calha e planície) do rio Paraguai reflete as mudanças ocorridas nas condições do sistema fluvial, em várias escalas temporais, associado à evolução geológica e climática da região e aos efeitos da atividade humana direta e indireta no canal.

Estudos realizados por Souza (2004), Silva et al. (2007), Silva et al. (2008), Silva et al. (2012) registraram relações entre os padrões de canal, tipos de sedimentos e evolução do sistema fluvial em diferentes compartimentos do rio Paraguai. Os autores verificaram maiores mudanças no segmento meandrante a partir da migração do canal a jusante da cidade de Cáceres. Nesse sentido, o objetivo do presente trabalho foi identificar a variação dos sedimentos de fundo em diferentes ambientes do sistema fluvial do rio Paraguai, a montante da cidade de Cáceres, a fim de avaliar seu comportamento 
em dois períodos do ano (cheia e vazante), considerando seu papel na evolução morfológica, a partir das formas de canal.

\section{ÁREA DE ESTUDO}

\section{MEIO FísıCO}

A área de estudo está embasada por encraves de diferentes formações geológicas e unidades geomorfológicas. O segmento corresponde a uma das principais entradas de água para o Pantanal mato-grossense, tendo como limites as bordas planálticas e delineamento da Província Serrana (Figura 01).

Figura 01 - Localização da área de estudo no contexto do Pantanal Superior em Cáceres - Mato Grosso, Brasil.

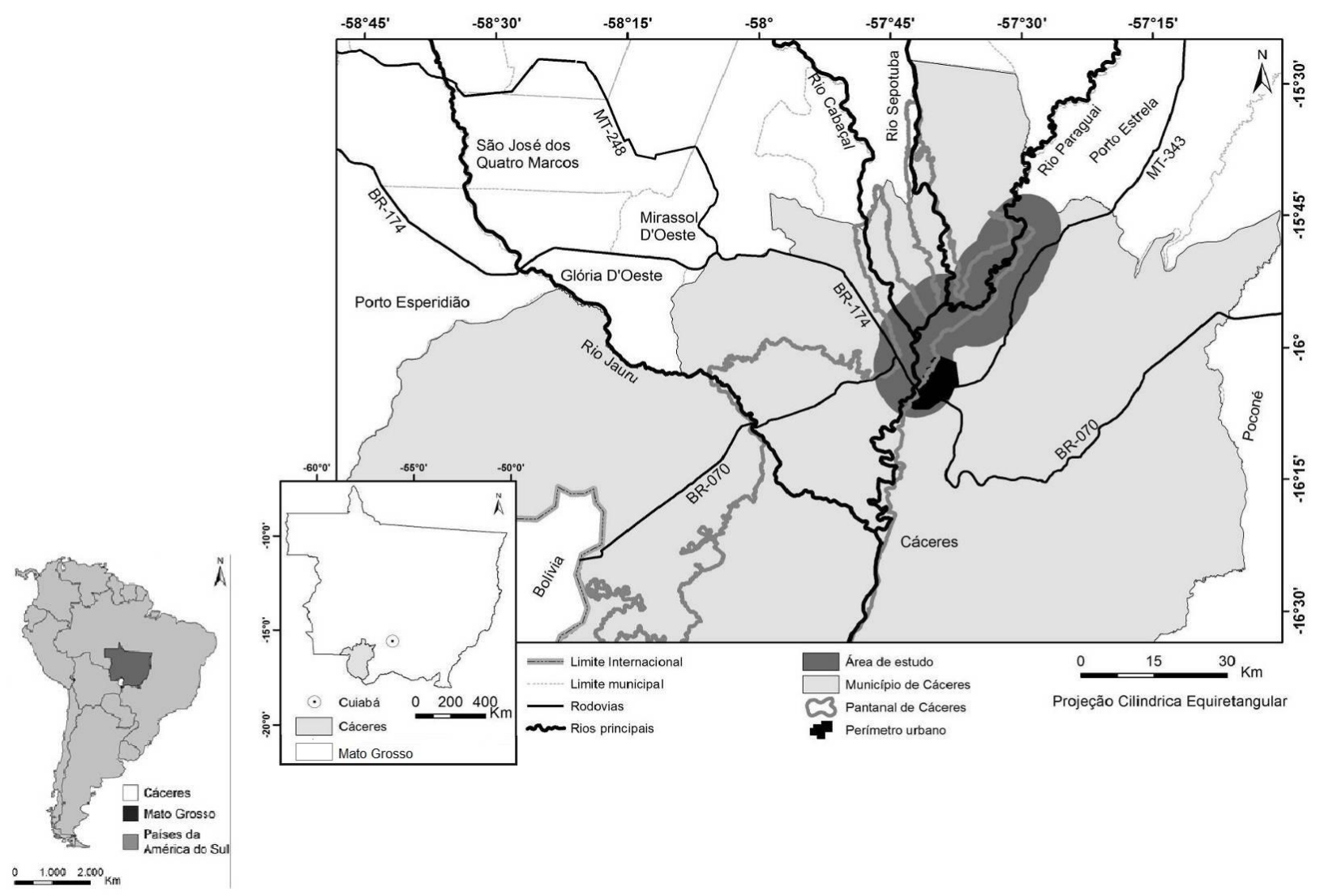

Org.: Gustavo Roberto dos Santos Leandro (2014).

O sistema fluvial do rio Paraguai percorre depósitos quaternários, constituídos por sedimentos inconsolidados. A base desses depósitos recentes é subdividida em Formação Pantanal - Qp e Aluviões Atuais - Ha. Ambos detêm maior representatividade em porcentagem, com 40,39\% e $44,86 \%$, respectivamente, e correspondem ao sistema agradacional na área de estudo. As Formações Raizama, Sepotuba e Araras estão presentes em 14,75\% da área em ambientes de dissecação. Os principais afluentes da margem esquerda do rio Paraguai percorrem o Sistema genético de denudação em drenagem encaixada nos vales da Província Serrana (Figura 02). A 
maioria deságua em feições morfológicas da planície de inundação. Com isso, a dinâmica no baixo curso dos afluentes é influenciada pelo rio Paraguai com os pulsos de cheia.

Figura 02 - Unidades litológicas e geomorfológicas presentes no corredor fluvial do rio Paraguai em Cáceres - Mato Grosso.

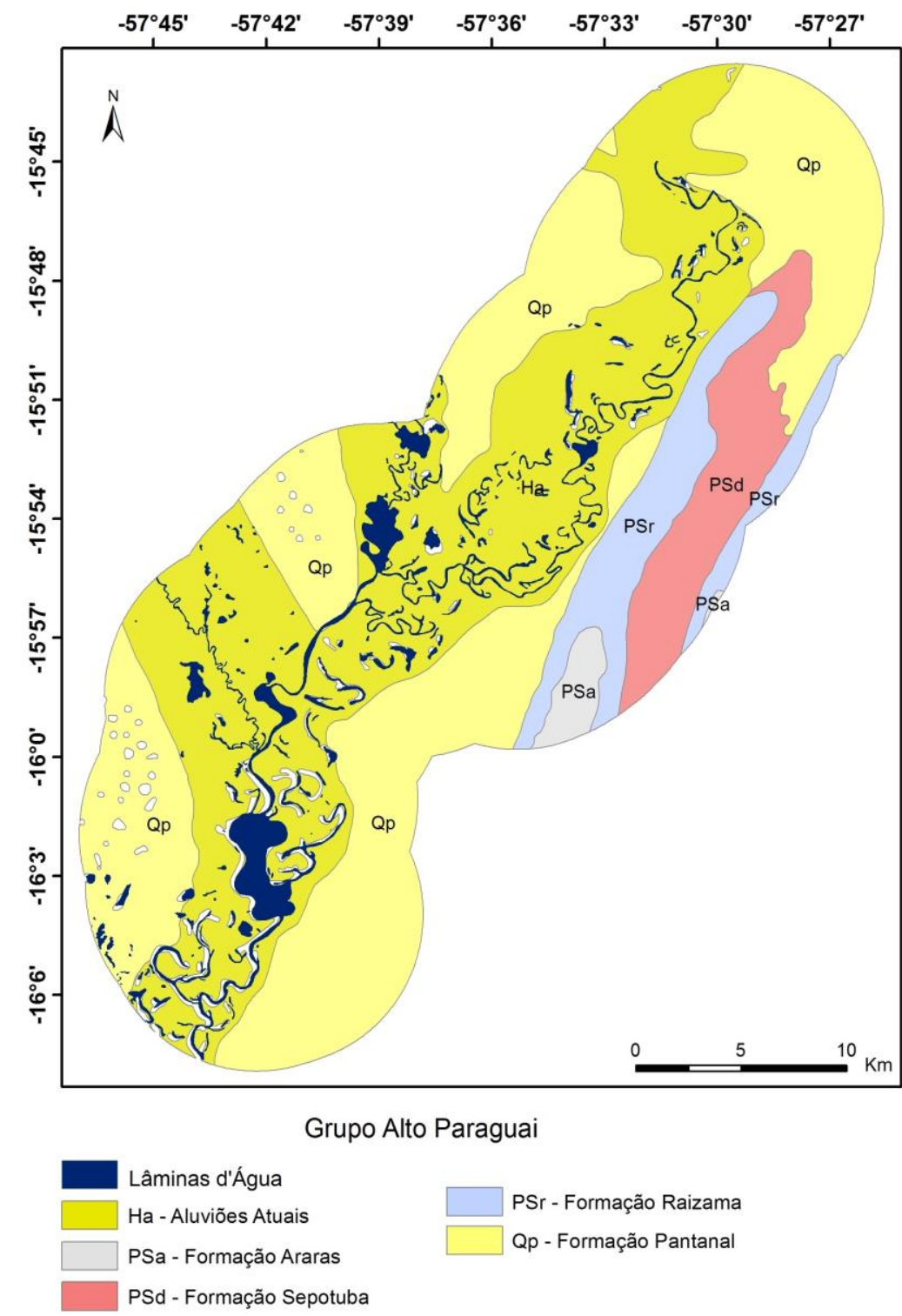

Fonte - Adaptado de CAMARGO (2011) e IBGE (2012). As siglas correspondem às formações litológicas.

Os afluentes da margem direita no baixo curso percorrem ambientes do Sistema Agradacional drenando o Pantanal de Cáceres na planície de inundação do rio Paraguai. Cada Sistema, neste caso, Denudacional e Agradacional, influencia de diferentes formas os processos fluviais e consequentemente o aporte e tipo de sedimentos que alcançam o rio Paraguai e sua planície de inundação. No primeiro, há o predomínio dos processos erosivos e de transporte de sedimentos grosseiros, conforme verificado por Souza (1998) e Santos (2013) em dois afluentes da margem esquerda, enquanto a deposição predomina nos afluentes da margem direita, de acordo com Justiniano e Souza (2010), processo aferido pela evolução das feições morfológicas da planície de inundação com a colmatação de baías e canais secundários. Fatores como Declividade, Altimetria e Extensão dos canais fluviais condicionam sua dinâmica através dos processos fluviais predominantes. 


\section{METODOLOGIA}

A fim de determinar os aspectos sedimentares no corredor fluvial do rio Paraguai, particularmente na sua extensão em território mato-grossense, foi desenvolvido um programa de amostragem de sedimentos de fundo no canal principal e em ambientes de confluência com dois dos principais afluentes, os rios Sepotuba e Cabaçal, no Pantanal Superior em Cáceres - Mato Grosso (Figura 03).

Figura 03 - Localização dos pontos e seções transversais selecionados para monitoramento.

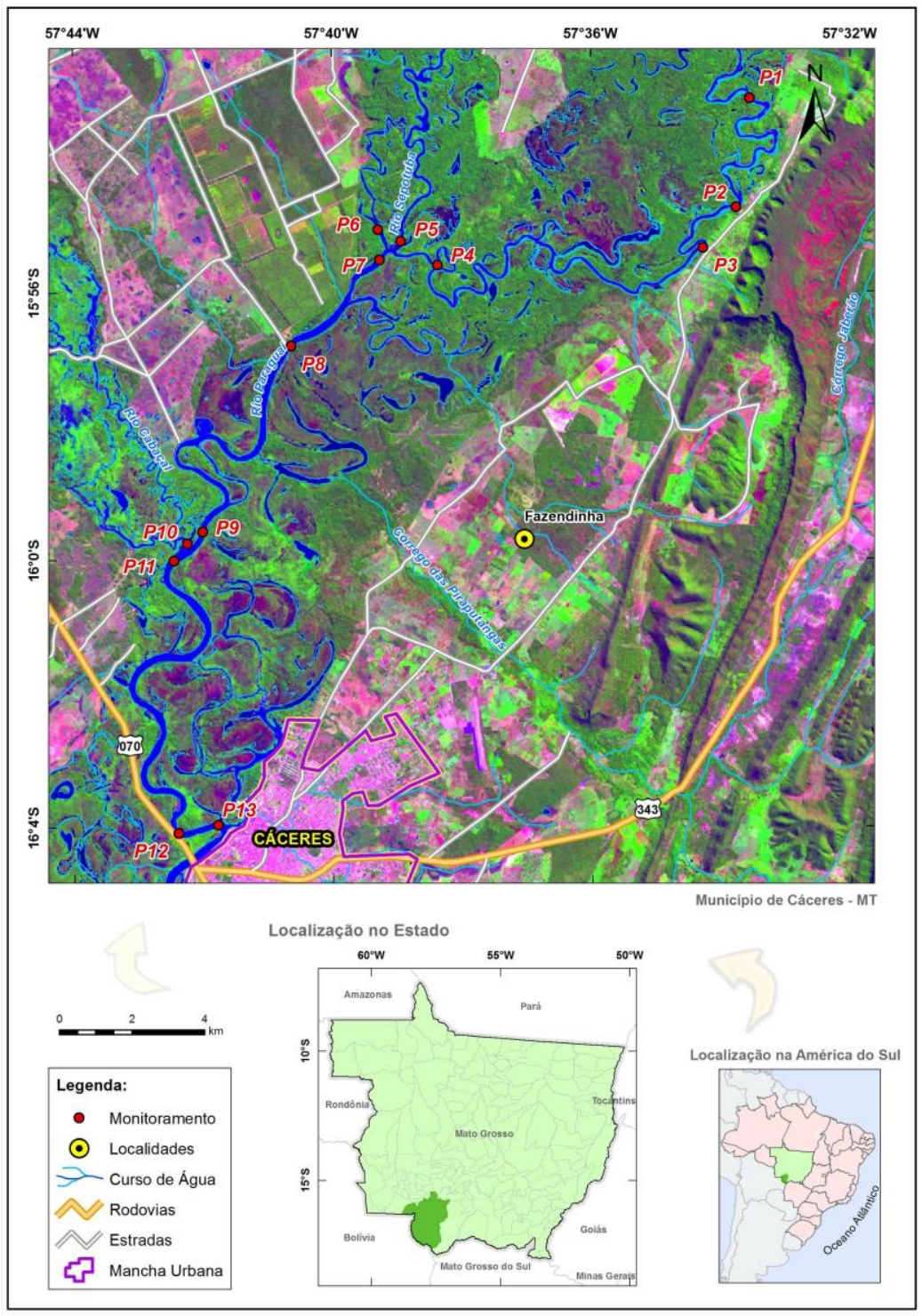

Fonte - Imagem LandSAT 7, 227/71, bandas 3-4-5 (2013). Org.: LEANDRO (2015).

A rede de monitoramento foi estabelecida com pontos de amostragem ao longo de 66,7 $\mathrm{Km}$ do percurso do rio Paraguai entre a Volta do Angical e a cidade de Cáceres - Mato Grosso. A seleção das seções para monitoramento e coleta de amostras de sedimentos foi baseada nos critérios assinalados abaixo (BÜHLER e SOUZA, 2012):

- Processos e ambientes fluviais (confluência e morfologia da seção transversal).

- Condição de acesso de acordo com o ciclo hidrológico.

- Uso do espaço pela população local e sua representatividade (dentro e fora do sistema de drenagem).

Caminhos de Geografia Uberlândia $\quad$ v. 21, n. 73 $\quad$ Mar/2020 $\quad$ p. 164-182 Página 168


Após esta etapa foi estipulada uma frequência de duas coletas dos dados de campo e seleção das variáveis a serem analisadas. Os trabalhos de campo foram realizados nos períodos de cheia e vazante nos anos de 2013 e 2014.

As amostras de sedimentos de fundo foram coletadas em seções transversais com auxílio do aparelho do tipo Van Veen (amostrador de mandíbulas) - margem esquerda, centro do canal e margem direita - de forma a caracterizar o talvegue e as porções laterais do canal (ROCHA e SOUZA FILHO, 2005). O material foi armazenado em sacolas plásticas de $2 \mathrm{Kg}$, as quais foram etiquetadas com dados da localização com auxílio de GPS (Sistema de Posicionamento Global), conforme as Figuras 04 e 05.

Figura 04 - Coleta de sedimentos de fundo em diferentes ambientes do sistema rio-planície de inundação.

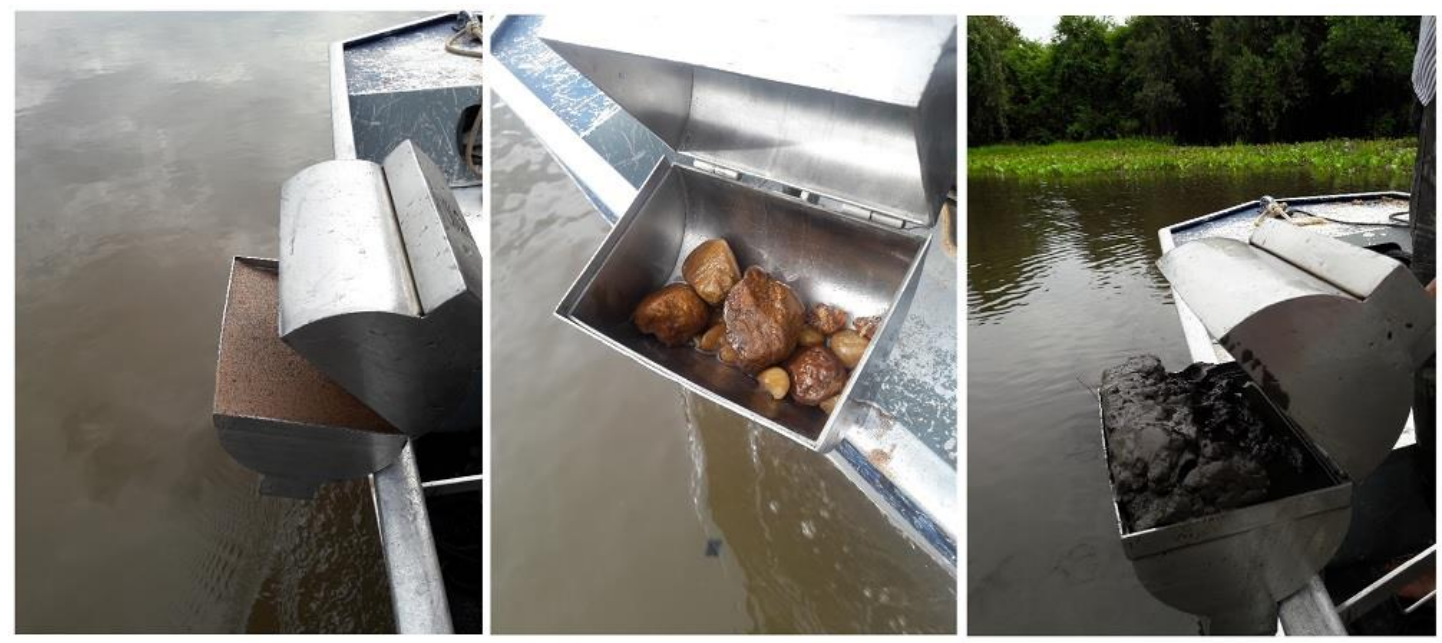

Fonte - os autores em trabalho de campo.

Figura 05 - Seção de canal com plano de amostragem dos sedimentos de fundo.

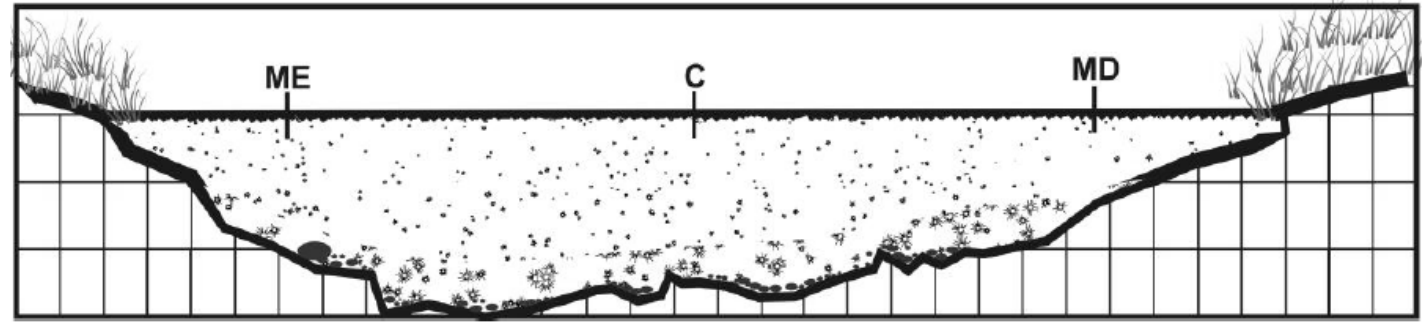

Fonte - Leli et al. (2010).

\section{Análise granulométrica}

A análise dos sedimentos considera as propriedades físicas, portanto os percentuais granulométricos quanto à ocorrência temporal e distribuição espacial ao longo do sistema fluvial. A quantificação e a classificação granulométrica são obtidas por Pipetagem e Peneiramento.

Para quantificar as frações argila e silte foi adotada a Pipetagem - dispersão total (EMBRAPA, 1997). Esse método é baseado nas mudanças de concentração de partículas em uma suspensão originalmente uniforme (SUGUIO, 1973). Os procedimentos constaram das seguintes etapas:

- Após secagem em estufa modelo TE-394/2, $20 \mathrm{~g}$ de amostra de cada ponto de coleta foi destorroada e condicionada em béqueres contendo $10 \mathrm{~mL}$ de solução dispersante $(\mathrm{NaOH} 0,1$ 
$\mathrm{m} \cdot \mathrm{L}^{-1}$ ) e água destilada (100 m. $\left.\mathrm{L}^{-1}\right)$. Em seguida, o conteúdo dos béqueres foi agitado com um bastão de vidro, fechado com um vidro de relógio e deixado em repouso por uma noite.

- Transcorrido o período de repouso, as amostras foram novamente agitadas mecanicamente durante 15 minutos no Agitador de Wagner TE-160. Na sequência, o material foi lavado em uma peneira de $20 \mathrm{~cm}$ de diâmetro e malha de 0,053 ( $\mathrm{n}^{\circ}$ 270) apoiada sobre um funil, que tinha logo abaixo uma proveta de $1000 \mathrm{~m} \cdot \mathrm{L}^{-1}$. As frações silte e argila passaram para a proveta de $1000 \mathrm{~m} . \mathrm{L}^{-1}$ e a areia ficou retida na peneira.

- O material da proveta foi agitado com um bastão de vidro por 30 segundos e deixado em repouso. Transcorrido o tempo de decantação, foi introduzida uma pipeta no interior da proveta até a profundidade de $5 \mathrm{~cm}$, sendo em seguida aspirada a suspensão (fração argila).

- Ao fim do processo, o material suspenso e a areia retida na peneira foram transferidos para béqueres identificados de acordo com o ponto de coleta e levados para a estufa modelo TE$394 / 2$.

- Concluída a secagem, foi realizada pesagem com balança analítica e calculados os valores de areia, silte e argila. A fração silte equivale à diferença da soma areia/argila dos $20 \mathrm{~g}$ iniciais. Foram realizados três ensaios por ponto de coleta para obtenção da composição média dos sedimentos depositados.

O material retido na peneira de $20 \mathrm{~cm}$ de diâmetro e malha de 0,053 ( $n^{\circ}$ 270) pela Pipetagem dispersão total foi seco em estufa. Posteriormente, foi submetido ao processo mecânico de Peneiramento no Agitador Eletromagnético, com uma sequência de peneiras padronizadas, por 30 minutos. O material retido em cada uma das peneiras foi pesado separadamente (SUGUIO, 1973).

\section{Evolução morfológica}

$\mathrm{Na}$ intenção de verificar mudanças morfológicas em ambientes do corredor fluvial, foram analisadas imagens disponibilizadas pelo Google Earth (período de 2002-2017). Para tanto, foram consideradas as confluências com dois dos principais afluentes - rios Sepotuba e Cabaçal, bem como ambientes da planície de inundação.

Os mapeamentos das mudanças morfológicas foram elaborados considerando a migração lateral do canal, classificação das feições morfológicas e a dinâmica dos ambientes de confluência.

Abordou-se a migração no corredor fluvial (canal e planície de inundação) a partir de análises de imagens de satélite de dois diferentes anos (1984 e 2013), perfazendo um intervalo de tempo de 29 anos. A migração do canal foi analisada a partir da sobreposição dos vetores extraídos das imagens de sensores orbitais. Além dos vetores, foram avaliadas as feições morfológicas produzidas pela migração do curso do rio, classificadas em negativas, tais como baías, lagoas e furado, a partir de etimologia regional adotada para o sistema fluvial do rio Paraguai, Pantanal (SOUZA, 2004; SOUZA et al.; 2009; SILVA et al. 2012).

\section{RESULTADOS E DISCUSSÃO}

Os sedimentos de fundo apresentaram granulometria heterogênea no período de cheia, mesmo com predomínio de material arenoso. Na amostragem realizada ao longo do perfil longitudinal, foi verificado que, a carga de fundo no sentido transversal apresentou frações de Areia Média e Areia Fina no setor Margem Esquerda. Cabe salientar que em P4 e P9 não houve sedimentos de fundo; e em P12, o material ocorrente foi de Areia Grossa, com 64,7\% (Figura 06). 
No Centro do Canal em P7 e P12 não ocorreram sedimentos de fundo devido à velocidade do fluxo. Com relação às demais seções transversais, a fração Silte ocorreu em P2, P9 e P10 (ambiente de confluência com o rio Cabaçal) com valores entre $70 \%$ e $90 \%$ da amostra total. Contudo, as frações arenosas ainda foram predominantes no perfil longitudinal considerando que constituíram valores acima de $90 \%$, à exceção de P13, em que se verificou $36,4 \%$ de Areia Grossa.

Os dados obtidos indicam que, em P4, os sedimentos de fundo estão concentrados no centro do canal, tendo em vista a não ocorrência nos setores marginais. Em P12, a morfologia côncava não permitiu a presença de material de fundo. Nas demais seções predominaram as frações arenosas com destaque para a Areia Grossa em P13. A fração Silte ocorreu predominantemente em P1, P8 e P11, com valores acima de 70\% (Figura 06).

Figura 06 - Classificação granulométrica dos sedimentos de fundo em seções transversais (Nov/2013).

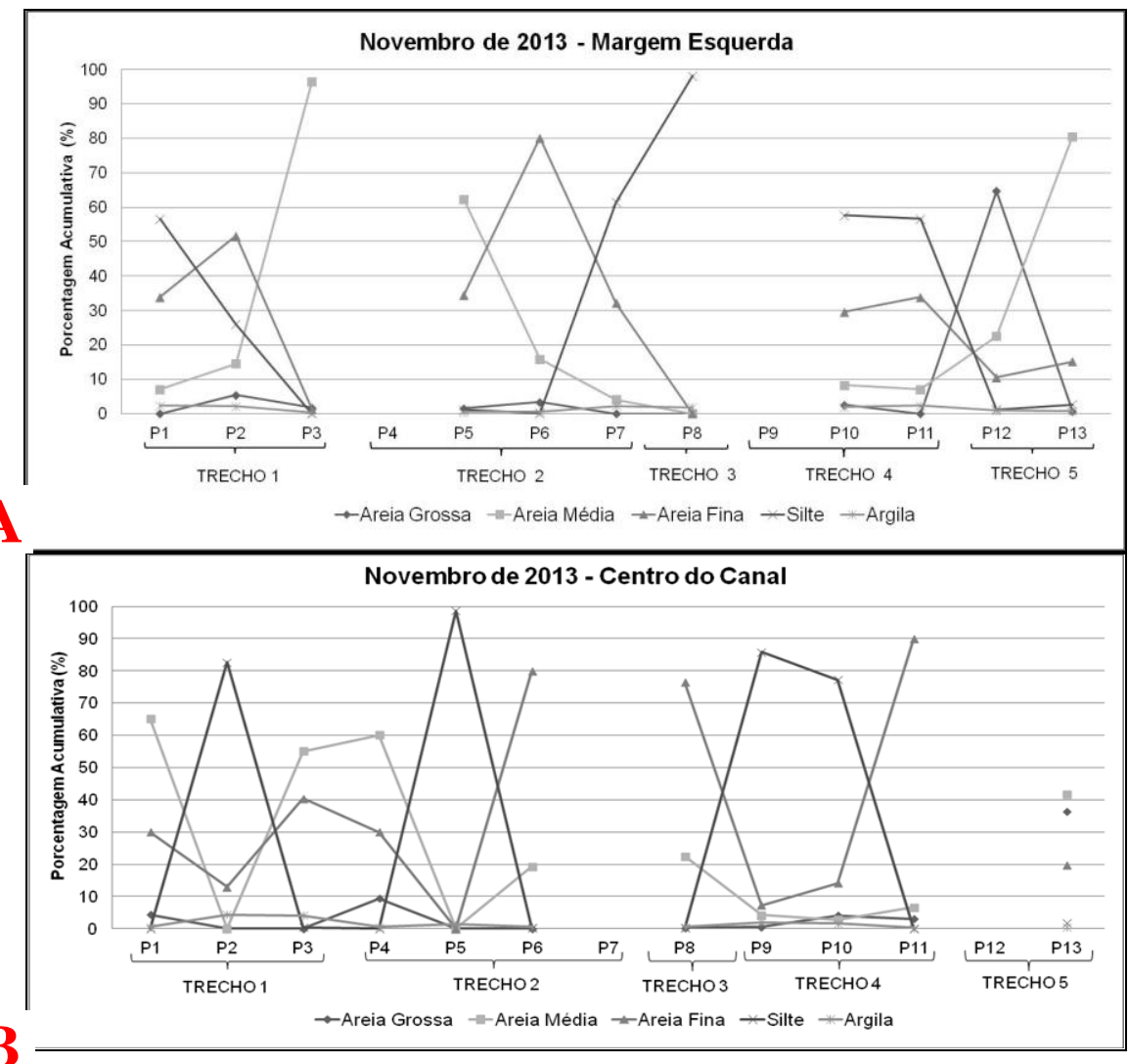

B

Novembro de 2013 - Margem Direita

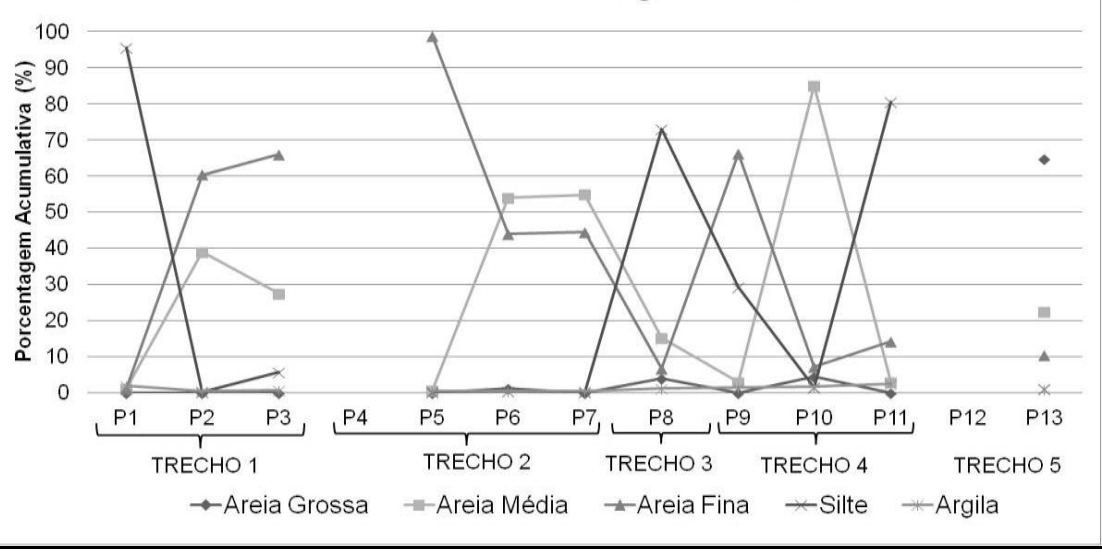

Fonte - Dados do(s) autor(es). 
Nas margens com morfologia convexa, os sedimentos arenosos, quando depositados, contribuíram para a sucessão de espécies pioneiras associadas a lâminas de frações finas (silte e argila) e matéria orgânica. Isso, porque a incoesão do material arenoso facilita o desenvolvimento do sistema radicular da vegetação pioneira que, com a deposição dos sedimentos finos e matéria orgânica, resulta no estabelecimento de espécies como o Sarã (S. obovatum), evidenciando sua importância como formador da mata ciliar dos rios pantaneiros (SIGAUD et al, 2007).

Os ambientes fluviais de confluência, nos Trechos 2 e 4, configuram intensa dinâmica de fluxo, diversidade nos materiais transportados, depósitos e suas remobilizações. No encontro dos rios Sepotuba e Paraguai, ocorreu maior peculiaridade devido à dinâmica do fluxo de ambos os canais. Nos períodos de monitoramento, o rio Sepotuba apresentou maior capacidade em volume, com vazões superiores ao rio Paraguai.

O ambiente de confluência dos rios Cabaçal e Paraguai, conhecido como Barra da Cabaçal, apresentou particularidades quando comparado à confluência dos rios Sepotuba e Paraguai, a montante. Também foram aferidas quando comparadas as seções transversais a montante e a jusante do afluente, sobretudo com relação à variação no nível da água. A partir dos levantamentos de campo, constatou-se que, no mês de Julho de 2014, houve aumento do nível da água em relação às margens do canal quando comparadas com as informações coletadas em Novembro de 2013. Tal processo foi divergente ao ocorrido nos demais trechos e suas respectivas seções transversais por apresentarem redução no nível fluviométrico. Um dos fatores que pode explicar o aumento do nível da água é a deposição de sedimentos, que nesse trecho, especificamente, se torna ativo com assoreamento no canal (Figura 07).

Figura 07 - Estabilização de barras laterais a montante e a jusante da confluência dos rios Cabaçal e Paraguai, Cáceres - Mato Grosso.
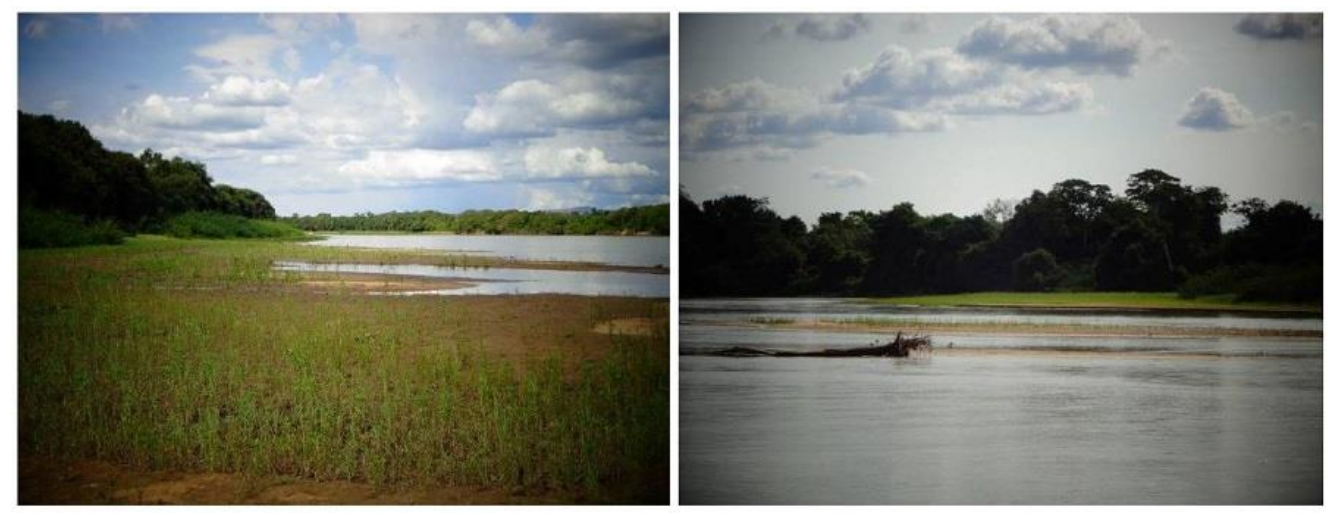

Fonte - os autores em trabalho de campo (2014).

No rio Araguaia, conforme Bayer e Zancopé (2014), os depósitos laterais são compostos principalmente por areias grossas a médias, com estruturas cruzadas e intercalações delgadas de materiais mais finos. Em ambos os sistemas, a estabilização dos ambientes fluviais, próximos ao canal principal, depende da composição dos sedimentos, de sua distribuição, da diminuição do volume de água, bem como do crescimento das espécies pioneiras.

Em Julho de 2014, período de vazante, os sedimentos de fundo ainda apresentaram composição arenosa. No entanto, a fração predominante foi a Areia Fina no setor Margem Esquerda, a qual ocorreu de forma uniforme quando considerada a composição granulométrica no perfil longitudinal. Os percentuais compuseram mais de $80 \%$ da amostra total com alcance de $99 \%$ em P7. A constituição do material de fundo foi composta ainda de fração Areia Média com valores acima de 10\% em P5 e P12 (Figura 08).

Quando considerado o Centro do Canal, verificou-se que nas três primeiras seções não houve material de fundo diferente do período anterior (Figura 08). Importante salientar ainda que em seções transversais onde não houve a presença de sedimentos de fundo, no período anterior, em Julho de 2014, ocorreu a deposição de sedimentos arenosos com percentuais acima de $80 \%$ de fração Areia Fina. 
Variação dos sedimentos de fundo e evolução morfológica no corredor fluvial do rio Paraguai, Cáceres - Mato Grosso
Gustavo Roberto dos Santos Leandro

Célia Alves de Souza

Flávio Rodrigues do Nascimento

No setor Margem Direita, a fração Areia Média ocorreu com valores expressivos em três seções transversais, com destaque para P13, acima de 40\% da amostra total. Em P2 e P3, os percentuais de Areia Fina ultrapassaram 95\%, sendo predominante ao longo do perfil longitudinal, assim como nos outros setores da seção transversal (Figura 08). Os resultados obtidos em Julho de 2014 indicam uma padronização nos sedimentos transportados e a sua ocorrência em setores em que no período anterior não foram registrados.

Figura 08 - Classificação granulométrica dos sedimentos de fundo em seções transversais (Julho/2014).

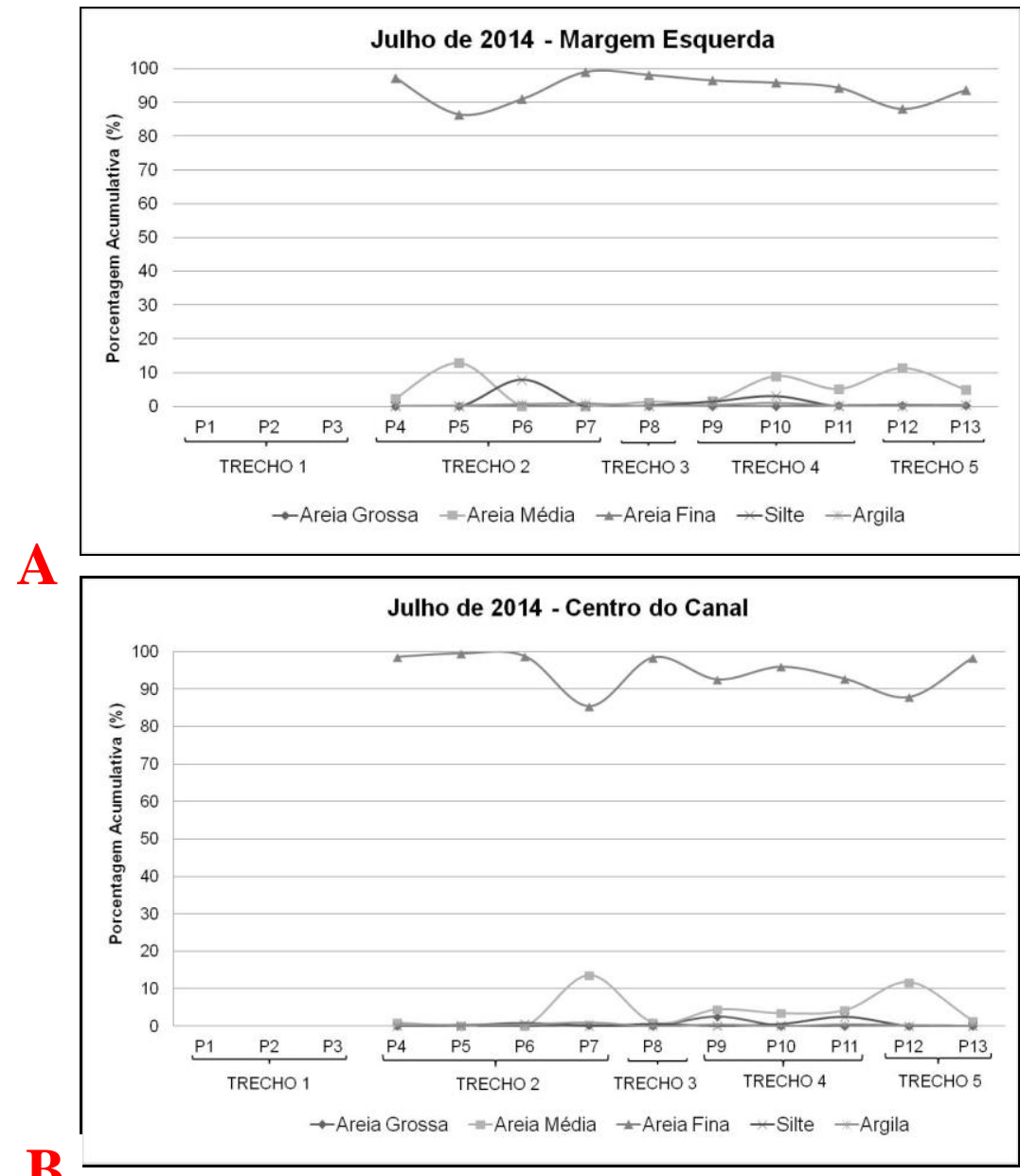

B

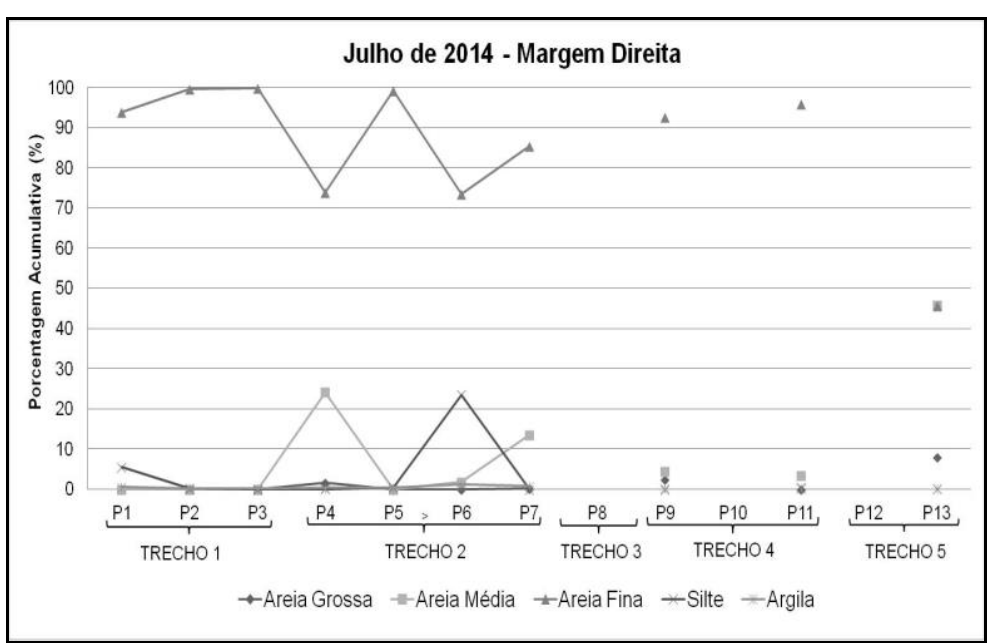

Fonte - Dados obtidos em laboratório sendo sistematizados em gabinete. 
A morfologia do canal possui particularidades quando comparada entre as seções em P12 e P13, o que pode ser explicado pela carga de sedimentos depositada e pela velocidade do fluxo que diminui de montante para jusante. As mudanças registradas ocorreram nos períodos de transição e, por isso, os processos de deposição podem apresentar ajustes ao considerar as sucessões de depósitos que ocorrem ainda no período final da vazante, ou seja, fase crítica de assoreamento. Tais processos foram verificados em vários rios aluviais e, em alguns casos, como indicadores de mudanças no sistema em escala maior com o ajuste fluvial e no padrão de canal (SILVA et al., 2008; GRIZIO e SOUZA FILHO, 2010; SOUZA et al., 2012; BAYER e ZANCOPÉ, 2014).

Os resultados obtidos indicam que no período de cheia ocorre maior remobilização de sedimentos com variação na granulometria, enquanto no período de vazante, o material de fundo apresenta maior homogeneidade textural com predomínio da fração Areia Fina em todas as seções monitoradas, o que indica perda da competência de transporte. A composição granulométrica da carga sedimentar de fundo contribui ainda para a diminuição da capacidade no sistema fluvial do rio Paraguai, o que pode ser aferido principalmente pelos depósitos laterais.

\section{Migração lateral e feições morfológicas}

A evolução no sistema fluvial do rio Paraguai decorre dos processos morfodinâmicos de esculturação, tendo como principais elementos condicionantes os depósitos aluviais que são retrabalhados e a hidrodinâmica que varia conforme o período hidrológico. Bayer e Zanconpé (2014) salientam ainda dois conjuntos de mecanismos que promovem a migração lateral recente em canais fluviais e evolução das feições morfológicas com destaque para os sistemas aluviais. Um deles está ligado aos processos de erosão marginal e outro aos processos deposicionais (BAYER e ZANCOPÉ, 2014).

As mudanças mais expressivas no sistema fluvial do rio Paraguai ocorreram no canal principal com o recuo de margem. Os processos erosivos são intensos em trechos retilíneos ou com morfologia côncava, sendo que no primeiro estão associados aos aspectos granulométricos das camadas inferiores e ao controle estrutural na margem oposta; e no segundo às mesmas condicionantes granulométricas, mas com destaque ao aumento do fluxo e ao impacto da corrente que se dá com diferentes intensidades ao longo do eixo côncavo. Grizio e Assine (2011) ao avaliarem a mobilidade no canal principal do rio Paraguai concluíram que as taxas de erosão foram superiores às de deposição com aumento de mobilidade lateral. Portanto, os processos de rompimento do meandro tornam o canal mais retilíneo com posterior reajuste no padrão meandrante e o surgimento de novas feições morfológicas na planície de inundação. Na sobreposição realizada, verifica-se o recuo em morfologia côncava na margem a montante e na subsequente, o que favorece o rompimento dos meandros (Figura 09).

A atuação e a intensidade dos processos de erosão de margens são intrínsecas às condições locais impostas pela hidrodinâmica dos fluxos e pela estabilidade relativa dos depósitos constituintes das margens do canal (BAYER e ZANCONPÉ, 2014). Portanto, as deposições recentes nas margens de rios aluviais, predominantemente arenosas na base, e de textura fina na planície, conferem baixa estabilidade a estas. Outros fatores como a morfologia e altura do barranco, em margem côncava, também contribuem para os processos erosivos, conforme verificado em estudo realizado por Souza e Cunha (2007).

Em contrapartida, os depósitos de canal e planície são a resposta ao transporte da carga sólida, e quando o sistema entra em estado de colmatação e assoreamento há um reajuste nos processos. Os fatores que contribuem com os mecanismos deposicionais podem ser variáveis como a própria constituição dos sedimentos transportados, a declividade no sistema fluvial, a redução da vazão e, ainda, o aumento no aporte de sedimentos associado à ocupação/uso da terra.

Caminhos de Geografia Uberlândia $\quad$ v. 21, n. 73 $\quad$ Mar/2020 $\quad$ p. 164-182 Página 174


Figura 09 - Migração lateral no sistema fluvial com destaque para o rio Sepotuba.

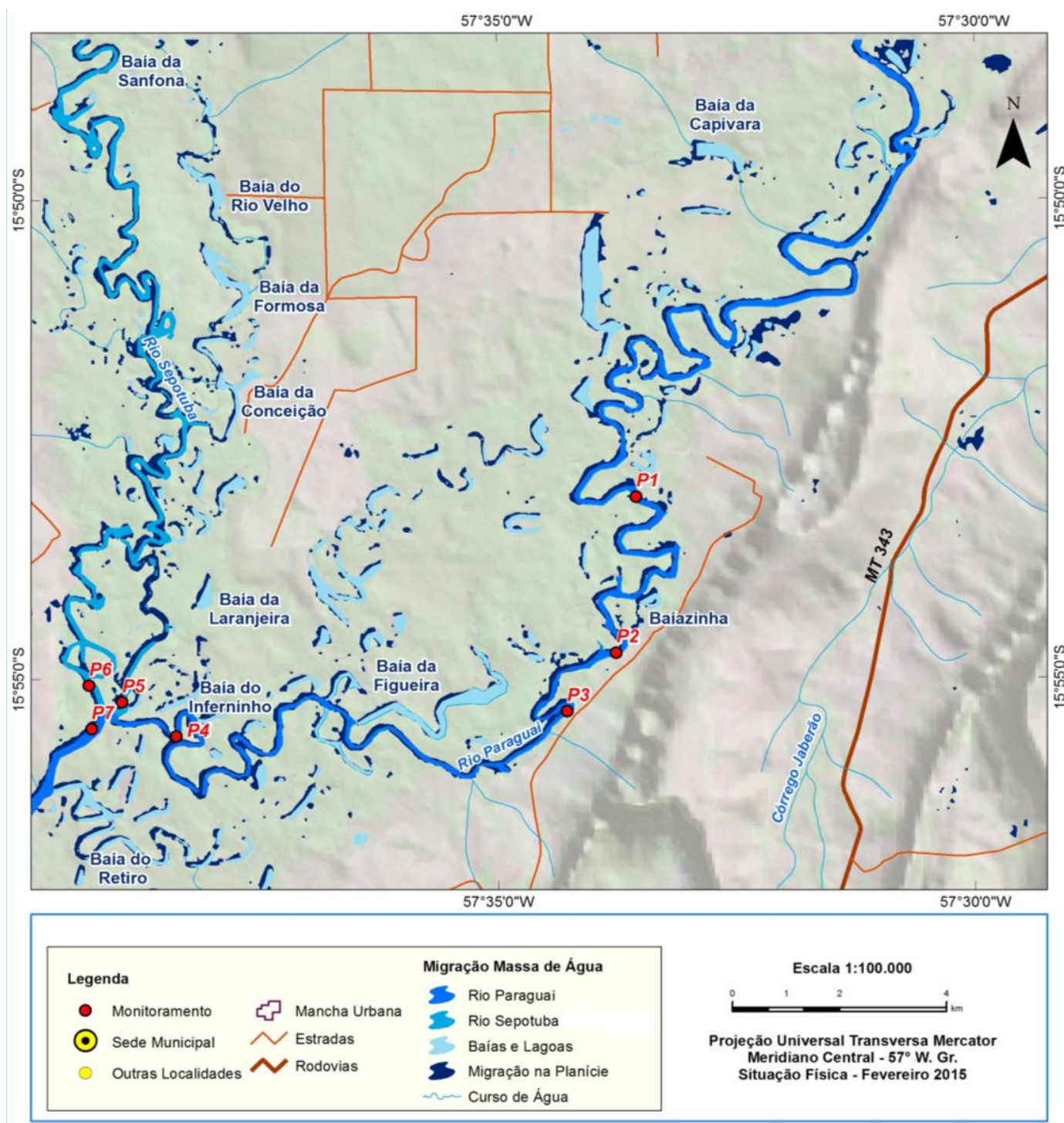

Fonte - LEANDRO (2015).

Entre a foz do rio Sepotuba e o perímetro urbano de Cáceres, no período entre 1984 e 2013, as principais mudanças no sistema fluvial foram a migração lateral em trechos retilíneos e em margens côncavas. A sobreposição espaço-temporal possibilitou a identificação de recuo marginal associado à composição e à estrutura do barranco, bem como à sua morfologia. No baixo curso dos afluentes, as mudanças foram expressivas, principalmente como surgimento de baías e lagoas. Verifica-se ainda a existência de bifurcações do canal associado ao transbordamento para a planície de inundação no período de cheia. Cabe salientar ainda a conexão de feições morfológicas denominadas de baías ao canal principal, pois ocorre a transferência do fluxo bem como a distribuição dos sedimentos com posterior deposição (Figura 10).

Ao adotar a dinâmica fluvial como variável de transformação da Paisagem, verificou-se que os processos erosivos e de deposição atuam como fatores responsáveis pelas mudanças na morfologia das seções monitoradas. Em P12 a morfologia da seção associada aos materiais constituintes - aqui destaque para as margens do canal e fundo - e à velocidade do fluxo resultaram na deposição de sedimentos com a formação de barra em pontal. A margem direita, consequentemente, apresentou processo inverso e complementar, ou seja, erosão por incisão vertical e lateral. Considerando o avanço da margem côncava sobre a BR-070, adotou-se a técnica de enrocamento a fim de conter os processos erosivos. Na Figura 11, observa-se o avanço da erosão sentido rodovia com recuo da 
margem para o período de 15 anos (Figura 11 - A e B), e o trecho (aproximadamente $1 \mathrm{~km}$ ) no qual foram realizadas as obras de engenharia para sua contenção (Figura $11-\mathrm{B}$ e $\mathrm{C}$ ).

Figura 10 - Migração lateral no sistema fluvial com destaque para o rio Cabaçal.

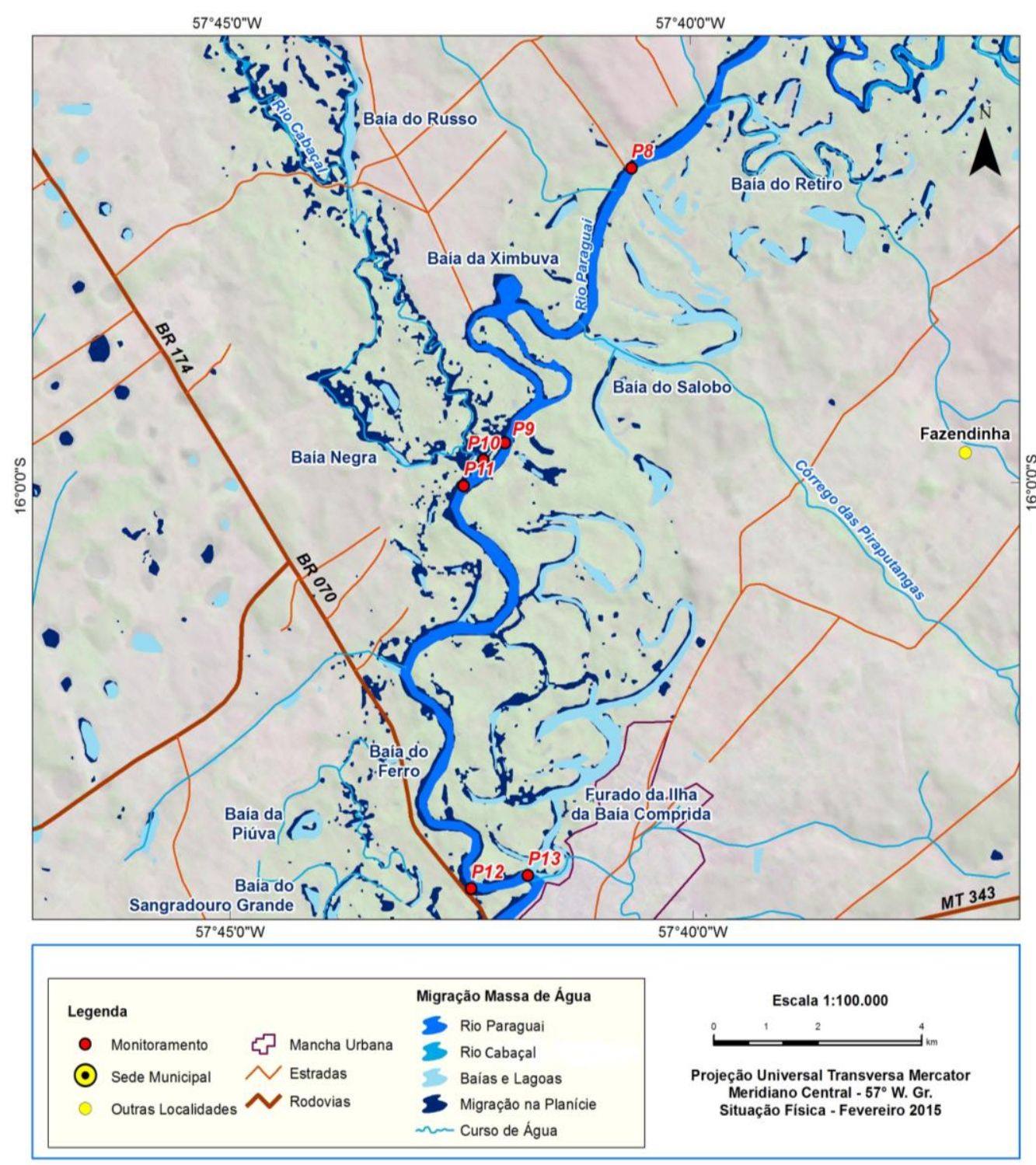

Fonte - LEANDRO (2015).

Figura 11 - Erosão marginal em P12 (2002-2017) com instalação de enrocamento no ano de 2014 (b).

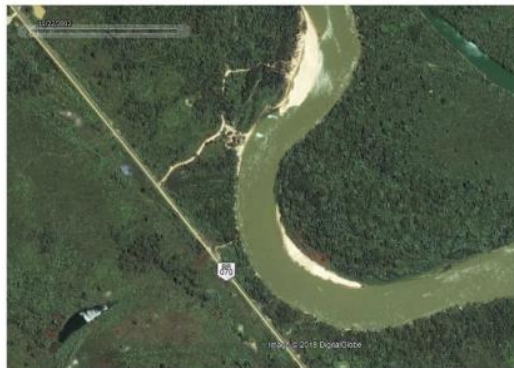

(a) 2002

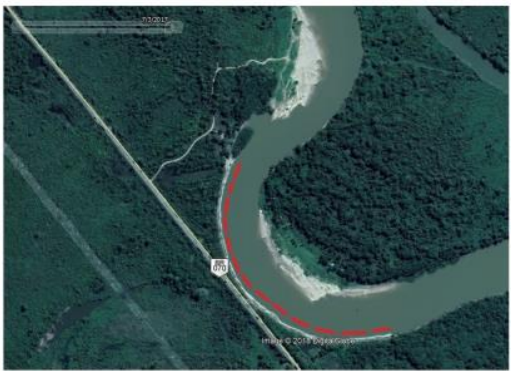

(b) 2017 - - Trecho com enrocamento



(c) início das obras (2014)

Fonte - imagens disponibilizadas pelo Google Earth (2017) e Jornal Oeste (2014). 
Os ambientes fluviais na planície aluvionar associados aos mecanismos de evolução têm relação direta com os aspectos de conectividade com o canal principal, o que pode ser aferido no período de cheia. As estruturas morfológicas secundárias têm sua manutenção condicionada pela transferência de fluxo e matéria, água e sedimentos, para canais secundários, abastecimento de baías, rompimento de meandro com o surgimento de furados e novos canais.

\section{Evolução morfossedimentar nos ambientes de confluência}

A evolução morfológica no corredor fluvial do rio Paraguai ocorre a partir do balanço hidrossedimentológico entre as cargas líquida e sólida. Na planície aluvionar desse sistema, se destacam como resultado de sua dinâmica as feições morfológicas positivas, em que predominam os processos naturais de acresção vertical, enquanto nas feições negativas, os processos de acresção horizontal.

O primeiro ocorre na planície de inundação proximal com a dinâmica do canal principal, sobretudo erosão e deposição em interação com as águas superficiais e sua variação fluviométrica. Enquanto o segundo ocorre na planície de inundação distal associado principalmente à dinâmica de subsuperfície com a flutuação do lençol freático, o qual abastece, por exemplo, baías e lagoas, sendo que as últimas não têm conexão com o canal principal. Contudo, o ambiente distal pode tornar-se ativo novamente pela migração lateral do rio Paraguai em sua planície aluvionar.

Nesse sentido, a estabilidade dos processos, bem como o estado de evolução dos ambientes fluviais, tem como bioindicador o tipo de vegetação associado a outros elementos, como a própria morfologia e as classes de solo. As espécies herbáceas desenvolvem-se em depósitos recentes como em barras laterais e em ambientes de colmatação, por isso são denominadas de "espécies pioneiras". No rio Paraguai, a Floresta Aluvial é composta por uma sucessão de subformações conforme as características do terreno no que diz respeito ao ambiente fluvial e feições morfológicas associadas.

Morais et al. (2008) destacaram que os tipos vegetacionais associados às ilhas e barras ao longo do canal do rio Araguaia também são diferentes ao considerar os ambientes do sistema aluvionar. Nas barras, verificaram que prevalece vegetação do tipo pioneira herbácea, enquanto nas ilhas, vegetação do tipo arbustivo-arbórea. A diversidade da cobertura vegetal nas geoformas reside no fato de que as ilhas, enquanto morfologias mais estáveis, evoluem por acresção lateral e vertical. A acresção vertical, no caso, favorece a deposição de sedimentos finos (silte/argila) sobre as bases arenosas, aumentando sua estabilidade e permitindo o desenvolvimento de vegetações de maior porte (MORAIS et al., 2008).

Na planície de inundação dos rios Sepotuba e Paraguai, observam-se em planta algumas feições negativas, principalmente lagoas e canais secundários. É possível verificar que a dinâmica sedimentar contribuiu para a evolução morfológica nos canais principais. Em 2006, o rio Sepotuba drenava dois canais, sendo o canal principal bifurcado por depósito arenoso em estágio inicial. Quando comparada a morfologia da confluência, entre 2006 e 2010, é possível observar a estabilização do depósito central e sua evolução para ilha fluvial com a sucessão de espécies herbáceas e acresção de sedimentos. Também foram identificados em vários pontos da foz do rio Sepotuba bancos de sedimentos que evoluíram anexos à planície em uma sucessão de diques marginais e cordões arenosos. No ano de 2013, o processo supracitado ocorreu onde as barras submersas foram anexas à planície, bem como à ilha fluvial, o que pode ser verificado pela cobertura vegetal herbáceo-arbustiva.

No entanto, os depósitos recém-anexados ainda estão sujeitos à inundação periódica, sendo dois os indicadores da dinâmica hidrossedimentar, as lagoas presentes na ilha fluvial e as espécies flutuantes e herbáceas presentes no ambiente fluvial (Figura 12).

Nesse contexto pode ser aferida a importância da composição granulométrica dos sedimentos de fundo, bem como a hidrodinâmica em sistemas aluviais. Conforme Bayer e Zancopé (2014), a presença de ilhas no canal do rio Araguaia está associada à continuidade do processo sedimentar. Tal processo gera primeiramente barras arenosas de centro de canal como consequência de fatores hidrodinâmicos, os quais promovem uma expansão e desaceleração dos fluxos, perda de capacidade

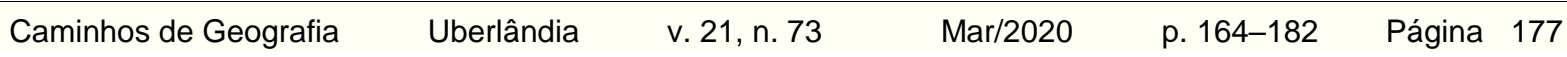


de transporte e acumulação de materiais predominantemente arenosos a montante e nas laterais das barras (BAYER e ZANCOPÉ, 2014). Diante disso, os aspectos sedimentares em rios aluviais ganham importância no que diz respeito à deposição com esculturação em diferentes ambientes.

Figura 12 - Evolução hidrossedimentar em ambiente de confluência entre os rios Sepotuba e Paraguai, Cáceres - Mato Grosso.
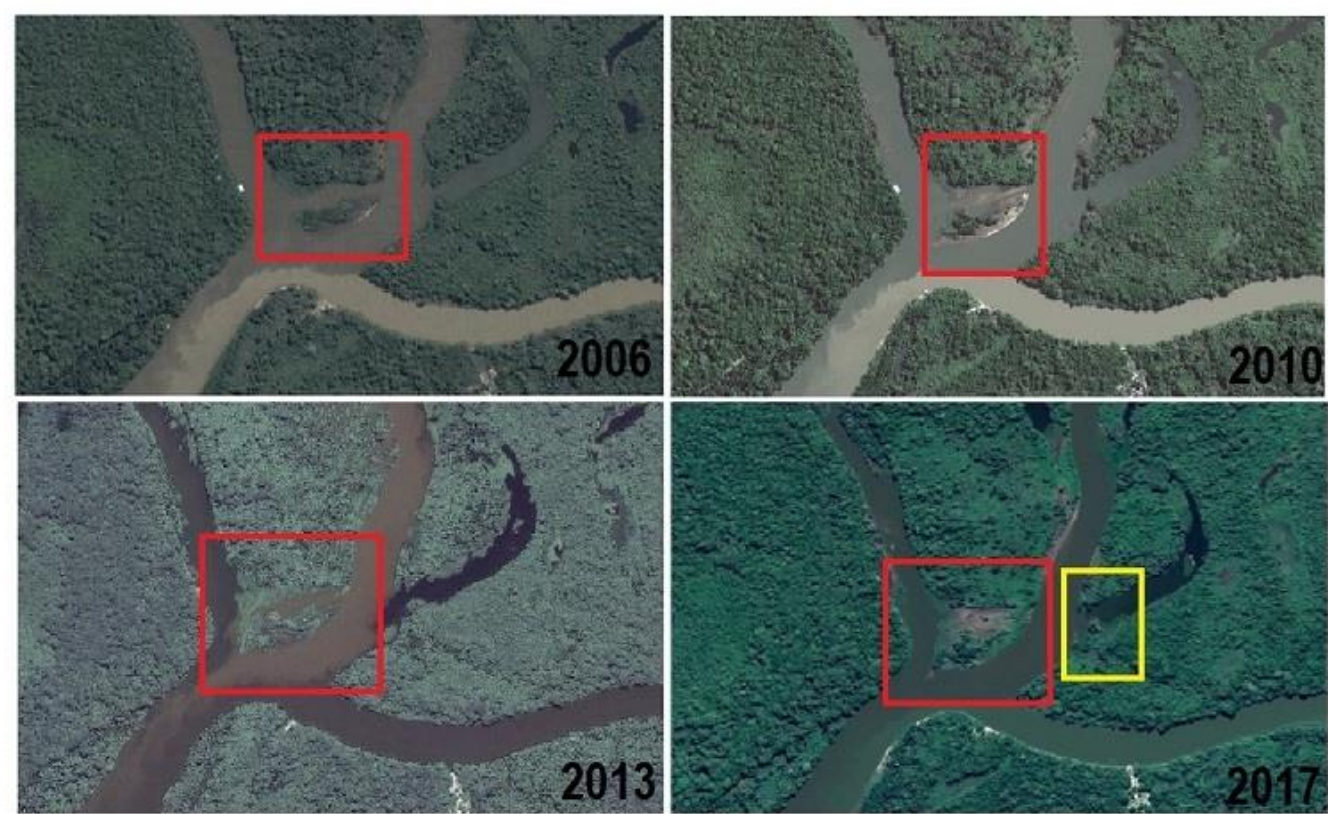

$\square$ Estágios evolutivos: barra central - ilha fluvial - início de estabilidade junto a planície de inundação.

Abandono de canal.

Fonte - Google Earth (2017).

No ambiente de confluência dos rios Cabaçal e Paraguai, a distribuição de espécies está diretamente associada aos processos fluviais. Na margem esquerda do rio Paraguai, ocorre predomínio de espécies arbustivo-arbóreas a arbóreas, aqui classificado como mata ciliar; enquanto na foz do rio Cabaçal e na margem direita do rio Paraguai (montante e jusante), há dominação de espécies arbustivas e herbáceas em razão da recente deposição de sedimentos, com o anexo da ilha fluvial à planície de inundação por acresção de barras laterais, no período entre 2006 a 2013. Morfologicamente, a confluência apresenta diversas feições negativas, tais como lagoas, baías, canais secundários e vazantes associados a depósitos recentes sujeitos à estabilização ou à remoção, dependendo do regime hidrológico.

Ao comparar temporalmente a evolução na foz do rio Cabaçal, são observadas alterações na morfologia dos depósitos, bem como em suas áreas com migração de barras. No ano de 2006, havia depósitos de sedimentos submersos, porém a ilha fluvial apresentou indícios de estabilização e incorporação à planície associado às barras laterais vegetadas por espécies pioneiras (Figura 13). Cabe destacar que o trecho é conhecido regionalmente como Barra do Cabaçal em razão da intensa deposição de sedimentos de fundo.

A partir do ano de 2010, ocorre a efetiva colonização das barras laterais que foram anexas à planície de inundação. Ao comparar as imagens dos anos de 2010 e 2013, observa-se ainda a colmatação do canal secundário do rio Cabaçal com a evolução de depósitos arenosos. A ilha fluvial foi acrescida lateralmente e verticalmente com mudança na cobertura vegetal, anteriormente herbácea; e em 2013, com características arbustivo-arbóreas (Figura 14). 
Figura 13 - Evolução hidrossedimentar em ambiente de confluência entre os rios Cabaçal e Paraguai, Cáceres - Mato Grosso.
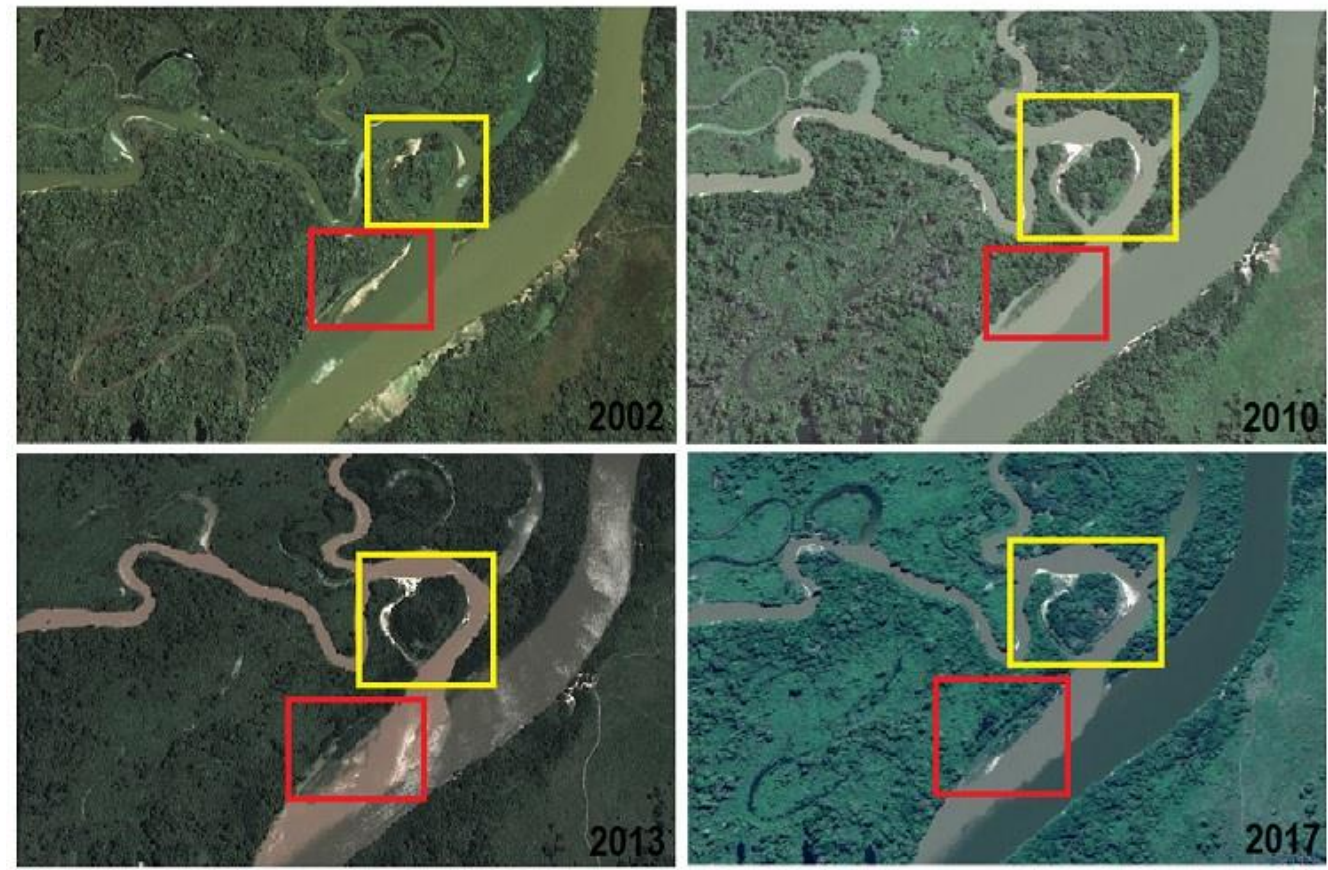

Evolução de barra lateral.

Dinâmica dos depósitos de sedimentos e evolução de ilha fluvial.

Fonte - Google Earth (2017).

Figura 14 - Acresção em barra de sedimentos na confluência entre os rios Cabaçal (direita) e Paraguai (esquerda), Cáceres - Mato Grosso.
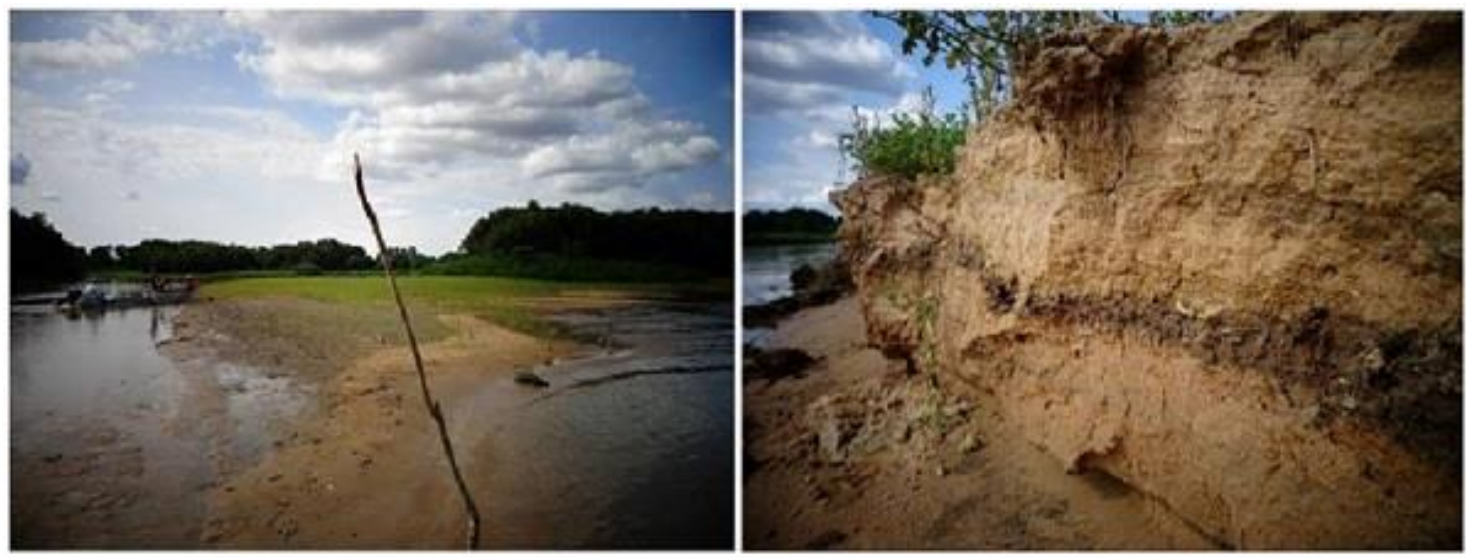

Fonte - os autores em trabalho de campo (2014).

Em estudo realizado no rio Araguaia, Bayer (2010) concluiu que os subambientes de bancos e ilhas acrescidas podem ser considerados como uma representação das condições "ambientais" atualmente operantes e dominantes na bacia. Conforme o autor, este subambiente reflete marcadas alterações cíclicas nas condições de deposição, como intervalos periódicos de exposição aérea. Ou seja, os depósitos localizados na seção superior das sequências sedimentares, nos bancos centrais e em outros setores do canal principal que ficam expostos a importantes variações anuais nas condições hidrodinâmicas dos fluxos (BAYER, 2010).

No rio Araguaia, Morais et al. (2008) verificaram que a unidade morfossedimentar de acresção de barras e ilhas está mais sujeita aos processos de remobilização sedimentar e, consequentemente,

$\begin{array}{lllll}\text { Caminhos de Geografia } & \text { Uberlândia } & \text { v. 21, n. 73 } & \text { Mar/2020 } & \text { p. 164-182 Página } 179\end{array}$


vegetacional, considerando o acelerado processo de atividade erosiva e sedimentar do canal. Os autores salientam ainda que pela sua instabilidade morfogenética e pelo condicionamento hidrológico (alta permanência de fluxos), este fato compromete o desenvolvimento de uma vegetação mais diversificada e de maior porte (MORAIS et al., 2008). Processo inverso foi verificado na confluência do rio Paraguai com seus afluentes, pois os ambientes de deposição, principalmente na foz do rio Cabaçal tem se estabilizado. Em contrapartida, áreas marginais do canal principal do rio Paraguai com vegetação de maior porte vêm apresentando intenso processo erosivo com quedas de blocos e solapamento basal.

As ilhas fluviais presentes nos ambientes de confluência nos Trechos 2 e 4 evoluíram a partir da deposição inicial em barras centrais. Contudo, ambas foram anexadas à planície de inundação devido à sucessão deposicional e vegetal. O progressivo desenvolvimento e estabilização morfossedimentar estão vinculados ainda à continuidade do processo sedimentar. Nesse sentido, Morais et al. (2008) concluíram que o controle imposto no meio físico pelas características morfológicas da planície aluvial e pelo funcionamento hidrológico do sistema fluvial (fatores abióticos) condiciona o surgimento e manutenção das unidades vegetacionais, que são indicadores de estabilidade.

Cabe ressaltar ainda que as confluências possuem particularidades no que diz respeito aos processos deposicionais. No ambiente com o rio Sepotuba, a deposição ocorre, em sua foz e no canal secundário, sendo verificada a presença de diques marginais, barras laterais e centrais com evolução de ilha fluvial. Enquanto no rio Cabaçal, mesmo com influência direta do rio Paraguai, os processos se intensificam a montante e a jusante da foz do afluente. As principais feições deposicionais apresentam estado de estabilização, sendo dique marginal, barra lateral e ilha fluvial anexada recentemente à planície de inundação.

\section{CONSIDERAÇÕES FINAIS}

As características de cada formação geológica constituinte contribuem para evolução dos sistemas agradacionais e denudacionais na área de estudo. Em suas interações e particularidades, cada subambiente vem sendo transformado em maior ou menor velocidade, aqui considerado o fator Tempo Geológico, pretérito e atual, sendo expressas espacialmente pelas feições e morfologia do relevo.

Como resultado de processos agradacionais estão as feições presentes no corredor fluvial do rio Paraguai, tais como barras laterais e ilhas fluviais. A alternância entre períodos de vazante e cheia é o fator principal na variação fluviométrica, o que corrobora para a deposição de sedimentos predominantemente arenosos de granulometria fina com valores acima de $70 \%$ no período de Julho de 2014 (Areia Fina). Com relação à evolução das feições positivas, foram identificadas alterações nos ambientes de confluência com a deposição de sedimentos, evolução de ilhas e posterior anexo à planície.

No segmento estudado, as mudanças fluviais relacionadas às seções transversais implicam em problemas à navegação. Junto a alterações morfológicas de fundo, se destaca a variação do talvegue, por exemplo. Sobre isso, a migração lateral do canal no período de 29 anos associado à evolução das feições morfológicas negativas no sistema canal-planície ganhou destaque. A incisão e deposição em diferentes pontos das seções transversais exigem o monitoramento constante não só da amplitude fluviométrica, mas também das barras de sedimentos (laterais, centrais, e primordialmente as submersas) e variações hidrossedimentológicas.

Assim, espera-se que os produtos gerados a partir das técnicas de representação geográfica, qualitativo e quantitativo, possam auxiliar no planejamento do uso no corredor fluvial do rio Paraguai e entorno. Destacamos, os cartográficos com a espacialização de elementos ambientais, e mudanças nos ambientes fluviais.

\section{AGRADECIMENTOS}

Os autores agradecem à Coordenação de Aperfeiçoamento de Pessoal de Nível Superior - CAPES pelo apoio financeiro e a REDE PRO-CENTRO-OESTE MCT/CNPq/FNDCT/FAPs/MEC/CAPES n. 031/2010 (2010- 2015).

\begin{tabular}{|c|c|c|c|}
\hline Caminhos de Geografia & Uberlândia & v. 21, n. 73 & Mar/2020 \\
\hline
\end{tabular}




\section{REFERÊNCIAS}

BAYER, M. Dinâmica do transporte, composição e estratigrafia dos sedimentos da planície aluvial do rio Araguaia. 2010. 82 f. Tese (Doutorado em Ciências Ambientais) - Universidade Federal de Goiás - UFG, Goiânia, 2010.

BAYER, M.; ZANCOPÉ, M. H. C. Ambientes sedimentares da planície aluvial do rio Araguaia. Revista Brasileira de Geomorfologia, São Paulo, v.15, n. 2, p. 203-220, 2014. https://doi.org/10.20502/rbg.v15i2.414

BÜHLER, B. F.; SOUZA, C. A. Aspectos sedimentares do rio Paraguai no perímetro urbano de Cáceres - MT. Geociências. v. 31, n. 3, p. 339-349, 2012.

CAMARGO, L. (Org.). Atlas de Mato Grosso: abordagem socioeconômico-ecológica. Cuiabá - MT: Entrelinhas, 2011. $96 \mathrm{p}$.

EMBRAPA - Empresa Brasileira de Pesquisa Agropecuária. Manual de Métodos de análises de solos. 2. E d. Rio de Janeiro: Embrapa Solos, 1997. 212 p.

GOOGLE. Google Earth Pro. Disponível em: https://www.google.com.br/earth/download/gep/agree.html. Acesso em novembro de 2017.

GRIZIO, E. V.; ASSINE, M. L. Mobilidade do canal no rio Paraguai Superior. Revista Brasileira de Geomorfologia. v. 12, n. 1, p. 71-80. 2011. https://doi.org/10.20502/rbg.v12i2.236

GRIZIO, E. V.; SOUZA FILHO, E. E. As modificações do regime de descarga do rio Paraguai Superior. Revista Brasileira de Geomorfologia. v. 11, n. 2, p. 25-33. 2010. https://doi.org/10.20502/rbg.v11i2.149

IBGE - Instituto Brasileiro de Geografia e Estatística. Manuais técnicos em Geociências: manual técnico de geologia. n. 1. 2 ed. Rio de Janeiro: IBGE, 2012. 271 p.

INPE - Instituto Nacional de Pesquisas Espaciais. Imagem de satélite Landsat 7, órbita 227, ponto 71. Composição colorida 5R-4G-3B. Agosto de 2013. Disponível em: http://www.dgi.inpe.br/CDSR/. Acesso em: agosto de 2013.

JUSTINIANO, L. A. A.; SOUZA, C. A. Evolução das margens e transporte de sedimentos no rio Paraguai entre a foz do rio Sepotuba e a foz do rio Cabaçal. In: SANTOS, J. E.; GALBIATI, C.; MOSCHINI, L. E. (Orgs.). Gestão e Educação Ambiental: Água, Biodiversidade e Cultura. vol. 3. São Carlos - SP: Rima Editora, 2010. p. 62-89.

JORNAL OESTE. Dnit dá início à obra que irá impedir avanço de erosão no rio Paraguai para rodovia. Cáceres - MT: 04 de Agosto de 2014 - Diário.

KUERTEN, S.; SANTOS, M. L.; SILVA, A. Variação das características hidrosedimentares e geomorfologia do leito do rio Ivaí - PR, em seu curso inferior. Revista Geociências. v. 28. n. 2, p. 143-151. 2009.

LEANDRO, G. R. S. Dinâmica ambiental e hidrossedimentológica no rio Paraguai entre a Volta do Angical e a cidade de Cáceres - MT. 145 f. Dissertação (Mestrado em Geografia) - Instituto de Geociências, Universidade Federal Fluminense - UFF, Niterói - RJ, 2015.

LELI, I. T.; STEVAUX, J. C.; NÓBREGA, M. T. Produção e transporte da carga suspensa fluvial: teoria e método para rios de médio porte. Boletim de Geografia. v. 28, n. 1, p. 43-58. 2010. https://doi.org/10.4025/bolgeogr.v28i1.8472

MILLIMAN , J. D.; YUN-SHAN, Q.; MEI-E, R.; SAITO, Y. Man's Influence on the Erosion and transport of sediment by asian rivers: the Yellow river (Huanghe) example. The Journal of Geology, v. 95, n. 6, 1987. https://doi.org/10.1086/629175

MORAIS, R. P.; AQUINO, S.; LATRUBESSE, E. M. Controles hidrogeomorfológicos nas unidades vegetacionais da planície aluvial do rio Araguaia, Brasil. Acta Scientiarum. Biological Sciences. v. 30, n. 4, p. 411-421, 2008. https://doi.org/10.4025/actascibiolsci.v30i4.5871

NITTROUER, J. A.; ALLISON, M. A.; CAMPANELLA, R. Bedform transport rates for the lowermost Mississippi river. Journal of Geophysical Research, v. 113, p. 1-16, 2008. https://doi.org/10.1029/2007JF000795 
NITTROUER, J. A.; SHAW, J.; LAMB, M. P.; MOHRIG, D. Spatial and temporal trends for water-flow velocity and bed-material sediment transport in the lower Mississippi River. Bulletin of Geosciences (print), v. 124, n. 3-4, p. 400-414, 2012. https://doi.org/10.1130/B30497.1

ROCHA, P. C.; SOUZA FILHO, E. E. Interações dinâmicas entre os materiais do leito de um canal secundário com o canal principal no trecho multicanal do Alto Rio Paraná, Brasil. Revista Brasileira de Geomorfologia. v. 6, n. 1, p. 19-32, 2005. https://doi.org/10.20502/rbg.v6i1.36

SANTOS, M. Uso, ocupação da terra e dinâmica fluvial da bacia hidrográfica do córrego Cachoeirinha no município de Cáceres - Mato Grosso. 2013. 150 f. Dissertação (Mestrado em Ciências Ambientais), Universidade do Estado de Mato Grosso - UNEMAT, Cáceres, 2013.

SIGAUD, C. G.; MACEDO, M.; NUNES, J. R. S. A importância do sarã (Sapium obovatum Klotzsch ex Mull. Arg.) no rio Piraim, Pantanal de Barão de Melgaço - MT. Uniciências. v. 11, p. 65-80, 2007.

SILVA, A.; ASSINE, M. L.; ZANI, H.; SOUZA FILHO, E. E.; ARAÚJO, B. C. Compartimentação geomorfológica do rio Paraguai na borda Norte do Pantanal mato-grossense, região de Cáceres MT. Revista Brasileira de Cartografia. v. 59, n. 1, p. 73-81, 2007.

SILVA, A.; SOUZA FILHO, E. E.; CUNHA, S. B. Padrões de canal do rio Paraguai na região de Cáceres (MT). Revista Brasileira de Geociências. v. 38, n. 1, p. 167-177. 2008. https://doi.org/10.25249/0375-7536.2008381167177

SILVA, E. S. F.; SOUZA, C. A.; LEANDRO, G. R. S.; ANDRADE, L. N. P. S.; GALBIATI, C. Evolução das feições morfológicas do rio Paraguai no Pantanal de Cáceres - Mato Grosso. Revista Brasileira de Geomorfologia. v. 13, n. 4, p. 435-442. 2012. https://doi.org/10.20502/rbg.v13i4.299

SOUZA, C. A. Bacia hidrográfica do córrego Piraputanga - MT: avaliação da dinâmica atual. 1998. 117 f. Dissertação (Mestrado em Geografia) - Centro de Ciências Matemáticas e da Natureza, Universidade Federal do Rio de Janeiro - UFRJ, Rio de Janeiro, 1998.

SOUZA, C. A. Dinâmica do corredor fluvial do rio Paraguai entre a cidade de Cáceres e a Estação Ecológica da ilha de Taiamã-MT. 2004. 173 f. Tese (Doutorado em Geografia) - Centro de Ciências Matemáticas e da Natureza, Universidade Federal do Rio de Janeiro - UFRJ, Rio de Janeiro, 2004.

SOUZA, C. A.; CUNHA, S. B. Pantanal de Cáceres - MT: dinâmica das margens do rio Paraguai entre a cidade de Cáceres e a estação ecológica da ilha de Taiamã-MT. Revista Eletrônica da Associação dos Geógrafos Brasileiros - Seção Três Lagoas. v. 1. n. 5, p. 18-42, 2007.

SOUZA, C. A.; LANI, J. L.; SOUSA, J. B. Questões ambientais: Pantanal mato-grossense. Cáceres - MT: Editora Unemat, 118 p. 2009.

SOUZA, C. A.; LEANDRO, G. R. S.; SOUSA, J. B. Migração lateral do canal do Rio Paraguai entre a cidade de Cáceres e a estação ecológica da llha de Taiamã - Mato Grosso. Geographia, v. 16, n. 31, p. 123-141, 2014. https://doi.org/10.22409/GEOgraphia2014.v16i31.a13675

SOUZA, C. A.; PIERANGELI, M. A.; SOUSA, J. B. Análise espaço-temporal do corredor fluvial do rio Paraguai no trecho entre Cáceres e a ilha Taiamã/MT. Revista Brasileira de Cartografia, v. 64, n. 5, p. 551-564, 2012.

SUGUIO, K. Introdução à sedimentologia. São Paulo: Edgard Blücher, 1973. 307 p.

Recebido em: 30/03/2019

Aceito para publicação em: 02/09/2019 